\title{
Sex Differences in Positive Well-Being: A Consideration of Emotional Style and Marital Status
}

\author{
Wendy Wood, Nancy Rhodes, and Melanie Whelan \\ Texas A\&M University
}

\begin{abstract}
This article reviews all published studies reporting tests for sex differences in well-being. Women were found to report greater happiness and life satisfaction than men. This sex difference was explained in terms of men's and women's social roles: The female (vs. male) gender role specifies greater emotional responsiveness. Furthermore, past role-related experiences provide women with appropriate skills and attitudes. Women's (vs. men's) greater well-being was also found to hold for married but not unmarried Ss: For both sexes the married state (vs. unmarried) was associated with favorable well-being, but the favorable outcomes proved stronger for women than men. Given that most Ss were married, the overall sex difference in well-being can be attributed to Ss' marital status. These findings were discussed in the context of prior research on sex differences in negative well-being.
\end{abstract}

Research on subjective social indicators has demonstrated that one's objective life circumstances do not necessarily correspond to one's personal experience of well-being. The fact, then, that men and women in our society differ in terms of a variety of biological, personality, and situational factors may or may not result in sex differences in subjective quality of life.

This article examines whether men and women do differ in evaluations of their life as a whole. The inquiry is limited to consideration of data on positive well-being and excludes findings on negative affect and psychological symptomatology. This is because positive and negative affect appear, under some circumstances, to be uncorrelated (Diener, Larson, Levine, \& Emmons, 1985; Warr, Barter, \& Brownbridge, 1983). ${ }^{1}$ Reports of positive well-being are best interpreted as indicators of positive domains of experience, separate from negative aspects of one's life circumstances.

Prior research on sex differences in subjective life quality has focused almost exclusively on negative affect and psychological symptomatology. Consequently, most theories in this area are tailored to explain the occurrence of men's and women's poor well-being. This work, and the data on which it is based, is presented as a frame of reference for interpreting sex differences in positive well-being.

First, we consider what is represented by judgments of wellbeing. Philosophers and psychologists have debated this question at length (see, e.g., Diener's, 1984, impressive review of the

This research was supported by Rockefeller Foundation Grant No. RF84036, Allocation 31, to the first author. The authors thank Monique Meeks for her assistance with library research, William A. Stock for his gracious assistance in providing the list of references from his own work, and Norval Glenn, George Levinger, Jamie Pennebaker, Jeffry Simpson, and Wendy Stock for their helpful comments on an earlier version of the manuscript.

Correspondence concerning this article should be addressod to Wendy Wood, Department of Psychology, Texas A\&M University, College Station, Texas 77843-4235. literature), but there are several points worth reiterating in the present context.

Judgments of well-being are presumed to reflect an overall evaluation of one's life circumstances. Such judgments are probably holistic, in that they reflect an overall disposition toward or against happiness and satisfaction, as well as particularistic, in that they reflect the outcomes of specific life domains, such as marriage, friendship, and parenting (cf. Diener, 1984). The holistic perspective reflects one's general approach to life and is supported by findings that a general positive or negative outlook permeates evaluations of more specific life domains. For example, some research suggests that satisfactions with various domains do not significantly differ in predicting overall life satisfaction, so that any domain performs about as well as any other (Andrews \& Withey, 1976). The particularistic perspective is supported by the alternate finding that when comparisons are made among categories of persons, evaluations of domains sometimes differ in their implications for aggregate well-being. For example, happiness with the domain of marriage has been found to be a more important predictor of overall happiness

\footnotetext{
' Diener and his colleagues (Diener, 1984; Diener et al., 1985) distinguished between frequency and intensity of emotional experience to explain the relation between positive and negative affect. At any given point in time, the experience of either positive or negative emotion apparently suppresses the experience of the other. Consequently, measures that tap frequency of emotional experience will tend to reveal that positive and negative affect are inversely related (e.g., Carroll, Feinberg, Smouse, Rawson, \& Greden, 1981; Warr et al., 1983). Intensity of these experiences, however, may be related such that people who tend to have intense positive emotions will also have intense negative ones (e.g., Epstein, 1983). Measures that tap emotional intensity are thus likely to observe a positive relation between the two classes of emotion. Finally, the measures of overall happiness or life satisfaction that are found most frequently in this review likely reflect both intensity and frequency of affect. Because frequency and intensity appear to combine in an additive fashion to produce mean levels of affect, these measures of positive well-being are likely to be statistically independent of assessments of negative aspects of experience.
} 
with life for women than for men (Glenn, 1975; Gove, Hughes, \& Style, 1983). In evaluating positive well-being, we consider both of these perspectives.

\section{Gender Roles and Emotional Experience}

According to one approach, sex differences in emotions and social behavior can be understood in terms of the social roles filled by women and men (Eagly, 1987; Eagly \& Wood, 1989; Williams \& Best, 1982). Men's and women's personal history of enacting social roles is an indirect cause of sex differences because of the influence that these experiences have on skills and attitudes. Sex differences also stem from shared beliefs about the likely and expected behavior of men and women, termed gender roles, which derive from the association between sex and social roles in the larger society. Thus, sex-differentiated prior experiences cause men and women to have somewhat different skills and attitudes, which, in conjunction with gender roles, cause sex differences in social behavior and emotions. This explanation of emotional experience in terms of social roles bears some similarity to "constructivist" approaches that view emotions as governed by social norms and rules (Averill, 1983).

The roles typically filled by men and women in our society differ importantly in terms of emotional experiences. Enactment of caretaker roles, which are typically filled by women in the home (e.g., mother, wife) and in paid employment settings (e.g., teacher, nurse), is likely to involve sensitivity to the needs of others and emotional expression. Men's roles are less likely to emphasize emotional experience. Prior role enactment and socialization for particular roles thus plausibly will instill beliefs and skills that lead women to be more sensitive to their own and others' emotions than men. In addition, the content of social stereotypes is informative about gender role expectations and emotions. Typical women are described as emotionally expressive, concerned with their own and others' feeling states, and emotionally labile (Broverman, Vogel, Broverman, Clarkson, \& Rosenkrantz, 1972; Ruble, 1983). Typical men, in contrast, are believed to be emotionally stable and not excitable. Thus women are attributed both greater emotional expressiveness and greater sensitivity to internal emotional events.

Given the emphasis on emotional experience in the female gender role, we anticipate that women will report more extreme levels of well-being than men. Indeed, women appear to report greater affective-type disorders than do men, including greater depression (Goldman \& Ravid, 1980; Nolen-Hoeksema, 1987) and greater personal discomfort and mental disorganization (Gove \& Tudor, 1973). This is not to say that women necessarily experience greater mental illness than men, because more men than women exhibit alcohol and drug abuse and personality disorders (Belle \& Goldman, 1980; Dohrenwend \& Dohrenwend, 1976, 1977; Weissman \& Klerman, 1977; however, see Cochrane, 1983).

Gender roles specify several possible sources of the sex differences in negative well-being. If women are more willing than men to report extreme emotions (cf. Phillips \& Segal, 1969), then data collected from community surveys, depression inventories, and treatment rates may reflect sex differences in admission of symptoms rather than true symptom rates. Gove and his colleagues (Clancy \& Gove, 1974; Gove \& Geerken, 1977; Gove, McCorkel, Fain, \& Hughes, 1976) attempted to assess response bias as an account of sex differences by estimating men's and women's perceived desirability of symptoms, tendency to say yes and say no, and need for social approval. Statistically controlling for these possible biasing factors did not reduce the observed sex difference in reports of symptomatology; women continued to report higher levels of disorder than did men. Although these investigations did not directly evaluate the mechanisms suggested by a gender-role analysis, they are informative in ruling out some artifactual influences on sex differences in reports of emotional events.

Several studies have attempted to directly manipulate the factors underlying willingness to report depressive symptomatology (Bryson \& Pilon, 1984; King \& Buchwald, 1982). Male and female college students were required to complete depression inventories under public or private disclosure conditions. The fact that disclosure setting did not affect reporting for men or for women in this research suggests that men's reluctance to publicly recognize symptoms may not underlie reported sex differences in depression. Yet some caution is appropriate in accepting this conclusion. Any sex differences in reporting are likely to depend on a variety of factors, such as the nature of the audience and the salience of gender-role norms. To what extent these operate to effect a general tendency for sex differences in reports of emotional experience remains unclear.

The female gender role also may specify that women be more attuned to actual emotional experiences than men. Again, this possibility has been invoked to explain women's higher incidence of certain types of mental illness. For example, treatment rates for depression may give a picture of excess pathology among women because, when men and women experience a comparable level of disturbance, women may seek medical assistance more than men. Women may seek assistance for a variety of reasons, including the fact that they more readily than men label low well-being and depressive symptomatology as emotional problems (Kessler, Brown, \& Broman, 1981). Alternatively, men and women may experience different psychological symptoms; with depression, men have been known to suppress overt depressive responses and focus on physical rather than psychological disorders (Hammen \& Padesky, 1977; Nolen-Hoeksema, 1987). ${ }^{2}$

Complementing this work on negative aspects of experience, several lines of research have obtained sex differences in a general tendency to indicate extreme emotional responses. Consistent with our expectations, women report more extreme positive and (nonsignificantly) more extreme negative feelings on Bradburn's Affect-Balance Scale (Bradburn, 1969), as well as

\footnotetext{
${ }^{2}$ Sex differences in treatment rates could also be due to the differential belief that psychiatric help is necessary or actually seeking treatment once a problem has been identified. Research is inconclusive on these points. Some studies report findings suggestive of no sex difference in these aspects of help-seeking (Amenson \& Lewinsohn, 1981; Belle, 1980; Gove, 1978; Kessler, Brown, \& Broman, 1981); others report that women seek treatment at a higher rate than men (Link \& Dohrenwend, 1980; Phillips \& Segal, 1969); and still others report that men are hospitalized for certain psychological disorders at a higher rate than women (Tudor, Tudor, \& Gove, 1977).
} 
on other measures of affect (e.g., Smith \& Kleugel, 1982). Women have also been found to report more extreme levels of fear, sadness, and joy than men (e.g., Allen \& Haccoun, 1976; Allen \& Hamsher, 1974; Balswick \& Avertt, 1977), although this sex difference does not seem to hold for reports of anger (Allen \& Haccoun, 1976; Averill, 1983). Sex differences also appear in the tendency to endorse extreme categories on scales tapping intensity of response. An earlier review concluded that, when significant sex differences appear, women typically exhibit more extreme responses than men (Hamilton, 1968). Similarly, at least one prior review of the literature on impression formation concluded that women use more extreme positive and negative evaluative terms than do men (Warr, 1971). ${ }^{3}$

However, two recent reviews examining positive well-being are not consistent with our argument that the female (rather than male) gender role involves greater emotional sensitivity and expressiveness. A recent narrative review included 13 studies that compared men's and women's judgments of life satisfaction and happiness and concluded that there appears to be no difference in reported mean levels of positive well-being (Diener, 1984). However, the small number of studies included in the review, along with the likely conservatism of narrative reviewing techniques (Rosenthal, 1984), might have led to an underestimate of any sex difference effects. In contrast, a more extensive meta-analytic review of 93 studies observed a slight tendency for men to report higher levels of well-being than women (Haring, Stock, \& Okun, 1984). The mean correlation between sex and well-being obtained in this review was $r=.04$ (95\% confidence interval $[\mathrm{CI}]=.01 / .07)$; controlling for socioeconomic status of the original participants did not appear to alter this relation. However, there is also reason to question these conclusions. The review included a number of summary measures of well-being that assessed psychological adjustment as well as multiple-item indices that tapped depression and psychosomatic complaints. Inclusion of data on negative well-being would be expected to have a major impact on the findings because of the large magnitude of sex differences in this domain. For example, a recent review by Nolen-Hoeksema (1987) reported women to be twice as likely as men to experience depression. Thus Haring et al.'s (1984) results favoring men plausibly reflect negative as well as positive well-being.

\section{Marriage and Well-Being}

The particularistic view of well-being noted earlier suggests that overall assessments of happiness and satisfaction with one's life are derived from evaluations of important life domains. We examined this perspective on sex differences in well-being by considering differences between men's and women's evaluations of two primary areas of life: marriage and employment.

Perhaps the most consistent finding concerning the state of marriage is its association with enhanced positive well-being and attenuated negative outcomes for both men and women. Married individuals report lower rates of psychological symptoms than do the unmarried, and they seek psychological services less frequently (Gove, 1972). The effects associated with marriage and positive well-being have been obtained with reported happiness, life satisfaction, and aggregate indices of the occurrence of positive and negative emotions (Bradburn, 1969;
Glenn, 1975; Gove et al., 1983; Haring-Hidore, Stock, Okun, \& Witter, 1985).

The benefits associated with marriage can be understood from the perspective of role accumulation. Potentially, marriage provides two additional roles, those of spouse and parent. Although multiple role occupancy was, in early work, linked to the experience of overload, conflicting demands, and psychological distress (Coser, 1974; Goode, 1960), recent analyses have emphasized the positive consequences of multiple role involvement (Marks, 1977; Sieber, 1974; Thoits, 1983, 1986). According to this view, multiple roles enhance perceived time and energy and confer a variety of rewards, including the privileges of the various roles, overall status security, resources for status enhancement and role performance, and personality enrichment and self-gratification. To the extent that marriage represents an increase in roles for men and women, the enhanced well-being associated with married (rather than unmarried) individuals can be understood as one example of the positive effects associated with multiple-role occupancy. ${ }^{4}$

\section{Sex Differences in Experience of Marriage}

The role of wife differs in a number of important ways from the role of husband, and we anticipate that subjective well-being varies as a function of these role differences and associated expectations. Specifically, wives (rather than husbands) are likely to prove particularly skilled in and to value highly the emotional experiences associated with marriage. Furthermore, marriage is typically deemed a more important event in our society for women than for men, as is implied by popular caricatures of marital roles (e.g., the eager bride and reluctant groom, the playboy bachelor and lonely old maid). A diverse set of findings from various literatures provides suggestive support for our analysis.

The idea that women may be particularly skilled at and may value emotional aspects of marriage is suggested by the consistent finding that both marriage partners tend to report that wives possess a better understanding of their husbands than husbands do of their wives (e.g., Campbell, 1981). Direct observations of conflict resolution in couples suggests that wives often play the role of emotional specialist. For example, in comparison with husbands, wives appear more likely to determine the characteristic level of negative affect in marriage (Notarius \& Johnson, 1982). In addition, evaluations of the reciprocity of

\footnotetext{
${ }^{3}$ The tendency for women to indicate more extreme judgments may not be uniform across positive and negative ends of the judgment scale. Specifically, women's judgments of others conform more closely than men's to the "Pollyanna effect," in that women are more likely to infer additional positive attributes when others are described positively and are less likely to infer additional negative attributes when others are described negatively (Kohn \& Fiedler, 1961; Warr, 1971).

${ }^{4}$ We recognize that marriage is also a unique role that conveys specialized advantages and disadvantages. For example, support from one's spouse may confer unique rewards, such as a particularly effective buffer to the stress experienced in other roles. Indeed, the greatest differences between the married and the unmarried have been noted when these persons are under conditions of economic hardship, social isolation, and the responsibilities of parenthood (Pearlin \& Johnson, 1977).
} 
affect within couples suggest that wives are more finely attuned to the quality of emotional interchange (Levenson \& Gottman, 1985).

Women's greater involvement in marriage is apparent from findings that happiness with marriage is a more important predictor of global happiness for women than for men (Glenn, 1975; Glenn \& Weaver, 1981; Gove et al., 1983). Similarly, in a previous report of how individual life domains contribute to overall happiness, married women's top four rankings concerned aspects of their marriage (i.e., being in love, marriage, partner's happiness, and sex life), whereas married men placed less emphasis on this aspect of their lives (rankings, in order, are personal growth, being in love, marriage, job or primary activity; Freedman, 1978). Additional evidence for women's investment in close relationships is provided by a review of the effects of confidant support on the experience of stress (Cohen $\&$ Wills, 1985). Women seemed to benefit from such support more than men, and the benefits appeared primarily with the availability of confiding husbands and boyfriends and not with other types of confidants. Furthermore, sex differences have been found in spouses' descriptions of marital relations. Women in successful marriages characterize the relationship as involving emotional security (i.e., affection, trust, and caring) more than men do, whereas men describe their marriage as involving loyalty (i.e., commitment to the future) more than women do (Reedy, Birren, \& Schaie, 1981).

We have argued that the female (rather than male) gender role emphasizes the emotional aspects of marriage and that women's (rather than men's) past experiences yield greater investment and higher skill level concerning such relations. Consequently, when positive well-being is assessed, we anticipate wives reporting greater emotional advantages associated with marriage than husbands. However, the available data are highly inconsistent. A recent meta-analytic review observed that men benefit more from the married (rather than unmarried) state, as indexed by reports of positive well-being, than do women (Haring-Hidore et al., 1985). However, this review drew on the data set, mentioned earlier, that appears to have included indices aggregating across positive and negative well-being. Thus the results are difficult to interpret. More supportive of our predictions are the results from national probability surveys that assessed reports of happiness. In a number of investigations spanning a 14-year period, married women reported greater happiness than married men (Bernard, 1972; Glenn \& Weaver, 1979, 1988).

The evidence relating marriage to sex differences in negative well-being is more consistent. A picture of the "grim mental health" of wives was popularized by Betty Friedan (1963) and Jesse Bernard (1972) and further promoted by social scientists adopting a feminist perspective (e.g., Seiden, 1976). Indeed, research focusing on negative well-being has found that married women experience higher rates of psychological disturbance than married men in treatment rates for psychological distress (Gove, 1972, 1978) as well as in self-reports of symptomatology (Aneshensel, Frerichs, \& Clark, 1981; Fox, 1980; Radloff, 1980). Such findings are consistent with our gender-role analysis because we anticipate that women will be particularly sensitive to the emotional distresses as well as rewards associated with marriage (see Dion \& Dion, 1985, Huston \& Ashmore, 1986, and Peplau, 1983, for more detailed discussions of differences between men's and women's intimate relations).

Our explanation for sex differences in the experience of marriage differs from prior accounts. For example, Bernard (1972) labeled the apparent inconsistency in findings of elevated levels of both distress and happiness among married women, in comparison with those among married men, the paradox of the happy housewife. In her view, women are taught to equate the marital role with happiness, and when positive outcomes are assessed, the women do not recognize that it is causing mental distress. A similar argument by Gove (1972) attributed wives' psychological distress to deficiencies associated with traditional roles, such as the following: (a) Married women typically have only one source of personal gratification, their family, whereas married men can derive rewards from both employment and family roles; (b) married women are typically responsible for housework, which is a low-prestige, unrewarding occupation; (c) housework is also an unstructured activity that allows married women to be self-absorbed and detached from the environment; (d) married women who are employed may experience role overload because they are also responsible for household chores, and they tend to hold low-prestige, unrewarding jobs; and (e) role expectations for married women are diffuse, and outcomes are highly dependent on others. Furthermore, housewives may experience frustration because they are typically not using the skills and training they acquired at school (Darley, 1976). These views differ from the present analysis in a number of features, perhaps most notably in implicitly according lesser validity to the positive than to the negative outcomes associated with the role of wife.

\section{Sex Differences in Experience of Being Single}

The idea that sex differences may exist in the well-being of the unmarried has received less research attention. Because the number and type of roles associated with the unmarried state for men and women should be highly similar, role theorists have anticipated few sex differences in well-being for single people (Gove, 1972). However, given that women in our society report closer and more intimate same-sex friendships than men (Reis, Senchak, \& Solomon, 1985) and that such relations are important to positive well-being, a difference favoring single women's mental health may be anticipated. Alternately, given that employment should have a major impact on the well-being of single individuals and that men typically have higher status, potentially more rewarding work roles than women, single men may experience greater well-being than women.

The available data on negative and positive well-being is not easy to summarize. Although some studies on psychological treatment rates and self-reports of symptomatology have found greater disturbance among single men (Goldman \& Ravid, 1980; Gove, 1972; Gurin, Veroff, \& Feld, 1960), others have found greater disturbance among single women (Aneshensel et al., 1981; Fox, 1980), others no difference (Thoits, 1986), and still others variability among types of single people, including divorced, widowed, and never married (Radloff, 1980). In research on happiness, the sex difference appears to have varied across time. In 1974, never-married men (in comparison with women) reported lower well-being, but in 1986, single men's 
well-being apparently increased, and the sex difference reversed in direction (Glenn \& Weaver, 1988).

\section{Present Research}

These ideas about the overall sex difference in well-being and the differential effects associated with marriage for men and women were tested in a meta-analytic review of previous research. When possible, we examined the effects associated with one other social role, employment status. Our data generally were uninformative with respect to this variable, and thus we consider employment only briefly in this report.

A number of respondent characteristics may plausibly affect any sex differences obtained. Age is one attribute reported in most studies, and one previous narrative review concluded that at younger ages the sex difference in well-being favors women but that in later years the sex difference favors men (Diener, 1984). Consistent with this reasoning about the elderly, a recent meta-analytic review observed a slight, positive association between age and well-being for both men and women except for older women; among older women, increases in age were associated with decreases in well-being (Stock, Okun, Haring, \& Witter, 1983). Age of the sample studied is thus evaluated as a possible moderator of sex effects.

The measurement procedures used to assess subjective wellbeing were also evaluated as moderators of any sex difference. Measures of well-being include life satisfaction, happiness, morale, positive affect, and direct reports of well-being. The relation among these various measures is open to debate. Life satisfaction is sometimes considered a cognitive assessment of well-being, in contrast to happiness and positive affect as more emotional responses (Campbell, 1981). Empirical evaluations of the structure of well-being have found variously that happiness and life satisfaction both contribute to a single cognitive dimension, with positive feelings providing a measure of affect (Andrews \& Withey, 1976), or that assessments of happiness form a separate dimension from a more cognitive measure, labeled self-evaluation (Bryant \& Veroff, 1982). An alternate view is provided by research that has simply correlated the various measures of positive well-being; this strategy has revealed reasonably high interrelations among the forms of assessment (e.g., Lohmann, 1977). In this review we evaluate the evidence for sex differences separately by type of measure.

Distinguishing among measures in our sample of studies was not always straightforward. In cases in which respondents' wellbeing was evaluated through direct assessments of, for example, happiness or life satisfaction, the appropriate category was obvious. In many cases, however, multiple-item measures of wellbeing were used, and item content was often similar for scales intended to tap different domains of positive well-being. Even more problematic, from our perspective, is that the multipleitem scales often included items that appeared to tap negative aspects of experience. We decided to include such assessments in our review because they constitute such a large portion of the available data on positive well-being, yet we anticipated that women's (in comparison with men's) greater well-being should be apparent only with measures that uniformly tap positive aspects of experience. It was difficult to anticipate the outcome for more heterogeneous assessment techniques.

\section{Method}

\section{Description of Data Set}

This meta-analysis included every published study (in English) that could be located that reported a measure of positive subjective wellbeing for men and women. The final sample consisted of a total of 93 studies that provided a comparison between male and female subjects for a measure of life satisfaction, happiness, morale, positive affect, or general well-being. We excluded measures that tapped psychological adjustment, mental illness, psychosomatic symptoms, or physical health.

The final sample of studies was drawn from previous literature reviews of research on subjective well-being (Diener \& Griffin, 1984; Haring et al., 1984) and from computerized searches of Psychological Abstracts from 1976 to 1985 and Sociological Abstracts from 1963 to 1985 using the key words life satisfaction, happiness, and well-being.

For each study, an effect size $(d)$ representing mean level of well-being was calculated from a test of the sex difference. This statistic represents the magnitude of an effect and is calculated from the difference between the means of the male and female groups divided by the within-group standard deviation assumed to be common to the two populations (Hedges \& Olkin, 1985). Effect sizes associated with greater male subjective well-being were given a positive sign, and those associated with greater female well-being were given a negative sign. Sufficient information was provided to calculate an effect size for 78 separate study samples. With seven studies, enough information was provided to compute effect sizes for two different techniques of assessment, and thus the total sample includes 85 effect size estimates.

In 11 reports, the effect size for the sex difference was calculated from an exact $F$ or $t$. For 26 reports, the effect size was calculated directly from means and standard deviations. In 13 reports the effect size was calculated from a correlation coefficient. Proportions were given in $\mathbf{3 3}$ reports, and effect sizes were calculated via probit transformations (Glass, McGaw, \& Smith, 1981). In two reports the effect size was calculated from $z$ scores.

Individual attributes such as educational level, race, and income tended not to be reported systematically in the sample of studies in our review, and thus it was not feasible to examine relations between such attributes and sex differences in well-being. One strategy in such a case is to aggregate across individual study samples (and thus across different educational levels, races, etc.) and assume that the aggregated effect size represents some average or typical outcome. There is reason to believe, however, that aggregating the study samples in our review would yield a biased representation of the U.S. population and thus potentially of the sex-difference effect. Studies of well-being have been conducted disproportionately on the elderly and on those experiencing psychological and physical disabilities. Furthermore, studies in our sample included several non-Western cultures and other specialized populations (e.g., high academic achievers, institutionalized adults). For this reason we decided to validate the analyses conducted on the total sample of studies with separate analyses on only those studies using samples representative of the U.S. population ( $n=18$ ). The validation studies included national probability surveys as well as random samples from more specific geographic regions of the United States (i.e., in those cases in which the sample was representative of a cross-section of the population). These analyses are reported only when they differ from the analyses on the total data set.

\section{Variables Coded}

The following variables were examined for each study in the sample: (a) date of publication, (b) mean age of subjects, and (c) type of wellbeing measure (life satisfaction, happiness, positive affect, or general evaluation-a broad category assessing morale, general well-being, and other single-item scales that could not be classified into one of the other 
Table 1

Studies Included in the Meta-Analysis

\begin{tabular}{|c|c|c|c|c|c|}
\hline \multirow[b]{2}{*}{ Study } & \multirow{2}{*}{$\begin{array}{c}\% \\
\text { total sample } \\
\text { married }\end{array}$} & \multirow[b]{2}{*}{$\begin{array}{l}\text { Dependent } \\
\text { measure }\end{array}$} & \multirow{2}{*}{$\begin{array}{l}\text { Adjusted } \\
\text { effect size }(d) \\
\text { for mean } \\
\text { well-being }\end{array}$} & \multicolumn{2}{|c|}{$\begin{array}{l}95 \% \text { confidence limits } \\
\text { for } d\end{array}$} \\
\hline & & & & Lower & Upper \\
\hline Alston \& Dudley $(1973)^{\mathrm{a}}$ & & General evaluation & 0.03 & -0.08 & 0.14 \\
\hline \multicolumn{6}{|l|}{ Baur \& Okun (1983) } \\
\hline 1980 sample & 25 & General evaluation & 0.28 & -0.24 & 0.80 \\
\hline 1977 sample & 25 & General evaluation & 0.49 & -0.03 & 1.01 \\
\hline Bradburn (1969) & 79 & Happiness & -0.05 & -0.12 & 0.02 \\
\hline Brand \& Smith (1974) & & General evaluation & -0.98 & -1.36 & -0.61 \\
\hline \multirow[t]{2}{*}{ Brayfield, Wells, \& Strate (1957) } & 74 & General evaluation & -0.33 & -0.74 & 0.08 \\
\hline & 74 & General evaluation & -0.04 & -0.45 & 0.37 \\
\hline \multirow[t]{2}{*}{ Briscoe (1978) } & 100 & Life satisfaction & 0.16 & -0.72 & 1.03 \\
\hline & 100 & Positive affect & -0.82 & -1.74 & 0.09 \\
\hline \multicolumn{6}{|l|}{ Briscoe (1982) } \\
\hline Physician's sample & 100 & Happiness & -0.36 & -0.75 & 0.04 \\
\hline Social Science Research Council sample & 81 & Happiness & -0.24 & -0.38 & -0.10 \\
\hline Bronzaft \& Hayes (1983) & 48 & General evaluation & 0.25 & 0.05 & 0.45 \\
\hline Bulatao (1974) & & Happiness & -0.02 & -0.42 & 0.38 \\
\hline Burke \& Weir (1976) & 100 & Life satisfaction & -0.48 & -0.68 & -0.28 \\
\hline Burke \& Weir (1978) & & Life satisfaction & 0.08 & -0.17 & 0.33 \\
\hline Cameron $(1972)^{\mathrm{a}}$ & & Happiness & 0.00 & -0.23 & 0.23 \\
\hline \multirow[t]{2}{*}{ Campbell, Converse, \& Rodgers $(1976)^{a}$} & 67 & Life satisfaction & 0.03 & -0.06 & 0.12 \\
\hline & 67 & Happiness & 0.13 & 0.04 & 0.22 \\
\hline \multicolumn{6}{|l|}{ Cantril (1965) } \\
\hline Israeli sample & & General evaluation & -0.15 & -0.26 & -0.04 \\
\hline U.S. sample & & General evaluation & -0.10 & -0.18 & -0.02 \\
\hline \multicolumn{6}{|l|}{ Cavan, Burgess, Havighurst, \& Goldhamer } \\
\hline (1949) & 45 & General evaluation & -0.15 & -0.26 & -0.04 \\
\hline Chilman \& Meyer (1966) & 50 & Happiness & -0.07 & -0.34 & 0.20 \\
\hline Chiriboga, Roberts, \& Stein $(1978)^{b}$ & 0 & Happiness & -0.23 & -0.46 & 0.00 \\
\hline Collette (1984) & & General evaluation & 0.08 & -0.05 & 0.21 \\
\hline Council on Aging (1972) & 46 & Happiness & -0.08 & -0.21 & 0.05 \\
\hline Crandall \& Kytonen (1980) & & General evaluation & 0.25 & -0.09 & 0.59 \\
\hline Critelli (1977) & 0 & Happiness & -0.35 & -0.71 & 0.01 \\
\hline Czaja (1975) & & General evaluation & -0.05 & -0.41 & 0.31 \\
\hline Dickie, Ludwig, \& Blauw (1979) & & General evaluation & 0.76 & 0.23 & 1.29 \\
\hline Dressler (1973) & 100 & Life satisfaction & -0.01 & -0.46 & 0.44 \\
\hline Flint, Gayton, \& Ozmon (1983) & & General evaluation & 0.39 & -0.10 & 0.87 \\
\hline Gilhooly (1984) & 73 & General evaluation & 1.06 & 0.15 & 1.96 \\
\hline Gilleard, Willmott, \& Vaddadi (1981) & & General evaluation & 0.06 & -0.56 & 0.68 \\
\hline Glenn $(1975)^{\mathrm{a}}$ & 74 & Happiness & -0.17 & -0.23 & -0.11 \\
\hline \multirow[t]{2}{*}{ Gove (1978) } & & Happiness & -0.11 & -0.19 & -0.03 \\
\hline & & General evaluation & -0.10 & -0.18 & -0.02 \\
\hline Grant \& Chappell (1983) & 42 & Life satisfaction & 0.38 & -0.03 & 0.79 \\
\hline Gurin, Veroff, \& Feld (1960) & 76 & Happiness & -0.08 & -0.16 & 0.00 \\
\hline \multicolumn{6}{|l|}{ Haavio-Mannila (1971) } \\
\hline Helsinki sample & 61 & Life satisfaction & -0.18 & -0.37 & 0.01 \\
\hline Rural sample & 50 & Life satisfaction & -0.23 & -0.40 & -0.05 \\
\hline Harding (1982) & & Positive affect & 0.07 & -0.06 & 0.20 \\
\hline Hayes \& Stinnett (1971) & 100 & General evaluation & -0.26 & -0.47 & -0.05 \\
\hline Hearn (1980) & & Positive affect & -0.23 & -0.43 & -0.03 \\
\hline Henley \& Davis (1967) & 39 & Life satisfaction & 0.03 & -0.30 & 0.36 \\
\hline Holahan \& Gilbert (1979) & 100 & Life satisfaction & 0.00 & -0.52 & 0.52 \\
\hline Hutchinson (1975) & 38 & Life satisfaction & 0.03 & -0.11 & 0.17 \\
\hline & 38 & Happiness & 0.03 & -0.11 & 0.11 \\
\hline Inglehart (1978) & & Life satisfaction & 0.00 & -0.03 & 0.03 \\
\hline Knupfer, Clark, \& Room (1966) & 77 & Happiness & -0.05 & -0.18 & 0.08 \\
\hline Kutner, Fanshel, Togo, \& Langner (1956) & 35 & General evaluation & 0.24 & 0.06 & 0.42 \\
\hline Lawton, Moss, \& Moles (1984) & 45 & General evaluation & 0.20 & 0.14 & 0.26 \\
\hline Lee (1978) & 100 & General evaluation & -0.08 & -0.27 & 0.11 \\
\hline Lee \& Ellithorpe (1982) & 81 & General evaluation & 0.03 & -0.17 & 0.23 \\
\hline Liang (1982) & & & & & \\
\hline North Carolina sample & 44 & General evaluation & 0.22 & 0.09 & 0.35 \\
\hline Wisconsin sample & 50 & General evaluation & 0.15 & 0.06 & 0.24 \\
\hline Minnesota sample & 48 & General evaluation & 0.17 & 0.07 & 0.27 \\
\hline National sample & 43 & General evaluation & 0.11 & 0.05 & 0.17 \\
\hline
\end{tabular}




\begin{tabular}{|c|c|c|c|c|c|}
\hline \multirow[b]{2}{*}{ Study } & \multirow{2}{*}{$\begin{array}{c}\% \\
\text { total sample } \\
\text { married }\end{array}$} & \multirow{2}{*}{$\begin{array}{l}\text { Dependent } \\
\text { measure }\end{array}$} & \multirow{2}{*}{$\begin{array}{l}\text { Adjusted } \\
\text { effect size }(d) \\
\text { for mean } \\
\text { well-being }\end{array}$} & \multicolumn{2}{|c|}{$\begin{array}{l}95 \% \text { confidence limits } \\
\text { for } d\end{array}$} \\
\hline & & & & Lower & Upper \\
\hline Lieberman $(1970)^{c}$ & & $\begin{array}{l}\text { General evaluation } \\
\text { General evaluation }\end{array}$ & $\begin{array}{l}-0.34 \\
-0.30\end{array}$ & $\begin{array}{l}-0.79 \\
-0.75\end{array}$ & $\begin{array}{l}0.11 \\
0.15\end{array}$ \\
\hline Lipman (1961) & 100 & General evaluation & 0.08 & -0.20 & 0.36 \\
\hline Lowry (1984) & 53 & Life satisfaction & -0.24 & -0.51 & 0.03 \\
\hline Lubinski, Tellegen, \& Butcher (1981) & & General evaluation & 0.02 & -0.28 & 0.32 \\
\hline Maddox \& Eisdorfer (1962) & & General evaluation & -0.23 & -0.48 & 0.02 \\
\hline Messer (1968) & 44 & General evaluation & 0.03 & -0.24 & 0.30 \\
\hline Mugford \& Lally (1981) & 100 & Happiness & -0.15 & -0.30 & 0.00 \\
\hline \multicolumn{6}{|l|}{ Mutran \& Reitzes (1984) } \\
\hline Married sample & 100 & Positive affect & -0.06 & -0.20 & 0.08 \\
\hline Widowed sample & 00 & Positive affect & -0.13 & -0.32 & 0.06 \\
\hline Nehrke, Bellucci, \& Gabriel (1977-1978) & & General evaluation & -0.36 & -0.72 & 0.00 \\
\hline Ochse (1984) & & General evaluation & 0.01 & -0.08 & 0.10 \\
\hline Palmore \& Luikart (1972) & 90 & General evaluation & 0.04 & -0.14 & 0.22 \\
\hline Phillips (1967) & & Happiness & -0.08 & -0.24 & 0.08 \\
\hline \multicolumn{6}{|l|}{ Rosenberg \& Chelte (1980) } \\
\hline 1975 sample $^{a}$ & 67 & Happiness & -0.05 & -0.15 & 0.05 \\
\hline 1977 sample $^{a}$ & 64 & Happiness & -0.10 & -0.20 & 0.00 \\
\hline Runyan (1980) & & General evaluation & -0.06 & -0.47 & 0.35 \\
\hline \multicolumn{6}{|l|}{ Schmitt, White, Coyle, \& Rauschenberger } \\
\hline$(1979)$ & & General evaluation & 0.10 & -0.11 & 0.31 \\
\hline Sekaran (1986) & 100 & General evaluation & 0.25 & 0.03 & 0.47 \\
\hline Shichman \& Cooper (1984) & 31 & Life satisfaction & 0.38 & 0.10 & 0.66 \\
\hline Shin \& Johnson $(1978)^{\mathrm{a}}$ & 69 & Happiness & -0.06 & -0.22 & 0.10 \\
\hline Snider $(1980)$ & 59 & Life satisfaction & 0.08 & -0.11 & 0.27 \\
\hline Tolor (1978) & & Positive affect & -0.27 & -0.54 & 0.00 \\
\hline \multirow[t]{2}{*}{ Veroff, Douvan, \& Kulka $(1981)^{a}$} & 63 & Life satisfaction & 0.04 & -0.04 & 0.12 \\
\hline & 63 & General evaluation & 0.10 & 0.02 & 0.18 \\
\hline Wenz $(1977)^{a}$ & 51 & Happiness & 0.15 & -0.13 & 0.43 \\
\hline White $(1979)^{\mathrm{a}}$ & 96 & Happiness & -0.15 & -0.27 & -0.03 \\
\hline Woods \& Witte (1981) & & General evaluation & -0.18 & -0.61 & 0.25 \\
\hline
\end{tabular}

Note. Effect sizes are coded so that positive numbers represent greater well-being of men and negative numbers represent greater well-being of women.

a This study used a representative sample of the U.S. population or of a specific region of the United States (e.g., Wisconsin). Thus it was included in the supplemental analyses conducted on studies with representative samples.

${ }^{b}$ This study used a representative sample of divorced individuals. Thus it was used in the representative sample analyses exploring the effects of marriage. It was not, however, included in the representative sample analyses examining the overall sex difference in well-being.

c College student sample only.

categories, along with a variety of multiple-item indices). ${ }^{5}$ The number of male and female subjects and the total number of subjects were also recorded. ${ }^{6}$

In order to evaluate the effects of marriage on well-being, the percentage of the total sample married was recorded. This percentage was used as a predictor of sex effects in the analysis. It was originally our intention to evaluate the effects of employment status as well as of marital status. Thus we also recorded the percentage of the total study sample employed. The data from each study are presented in Table 1 .

\section{Results}

\section{Mean Level of Well-Being}

The attributes of the studies included in our analysis are presented in Table 2. The mean of the 85 effect size findings was computed by first weighting each estimate by the inverse of its variance (Hedges \& Olkin, 1985). Overall, no significant difference was obtained between women and men $(d=-0.01$, $95 \% \mathrm{Cl}=-0.02 / 0.00)$. The homogeneity statistic $\left(Q_{\mathrm{w}}\right)$ reveals whether the inconsistency in findings across study outcomes is large enough to reject the hypothesis that they are drawn from a common population (Hedges \& Olkin, 1985). This estimate has an approximate chi-square distribution with $k-1$ degrees of freedom, in which $k$ is the number of effect sizes. As would be expected, given the diverse attributes of studies in the present sample, effect size findings varied significantly across the sample $\left(Q_{\mathrm{W}}=355.47, p<.001\right)$.

Representative sample. A significant sex difference was obtained with the studies using representative samples of respon-

\footnotetext{
${ }^{5}$ A small number of single-item scales of morale and general wellbeing, which might have tapped a unipolar positive dimension, were included in this category. We located too few such scales to assign them to a unique category.

${ }^{6}$ In addition, the sex of the authors and the nationality of the subjects were coded and analyzed. No interpretable results were obtained as a result of these predictors.
} 
Table 2

Summary of Study Attributes

\begin{tabular}{lcc}
\hline \multicolumn{1}{c}{ Attribute } & $\begin{array}{c}\text { Studies with } \\
\text { known effect size }\end{array}$ & $\begin{array}{c}\text { Studies with known } \\
\text { effect size and } \\
\text { representative sample } \\
\text { of respondents }\end{array}$ \\
\hline Number of study findings & 85 & 18 \\
Median year of publication & 1978.0 & 1976.5 \\
Median number of respondents & 414.0 & 1504.5 \\
Mean age of respondents & 53.0 & 42.3 \\
Median \% married respondents & 63.0 & 65.5 \\
\% each type of well-being measure & & 72.2 \\
Happiness & 22.4 & 16.7 \\
Life satisfaction & 25.9 & 0.0 \\
Positive affect & 7.1 & 11.1 \\
General evaluation & 44.6 & \\
\hline
\end{tabular}

dents $(n=18)$. Women reported more favorable outcomes than men $(d=-0.05,95 \% \mathrm{CI}=-0.07 /-0.03)$. A significant amount of variability was present in this grouping of studies $\left(Q_{\mathrm{W}}=\right.$ $70.27, p<.05$ ).

Type of well-being measure. Analyses were conducted to examine whether the mean level sex difference varied with the type of measure used to assess well-being. Measures of life satisfaction $(n=17)$ and happiness $(n=22)$ yielded more favorable outcomes for women than for men $(d=-0.03,95 \% \mathrm{Cl}=$ $-0.05 /-0.01$, and $d=-0.07,95 \% \mathrm{CI}=-0.09 /-0.05$, respectively). Positive affect $(n=6)$ yielded a nonsignificant trend in the same direction $(d=-0.07,95 \% \mathrm{CI}=-0.15 / 0.01)$. However, general evaluation $(n=40)$ yielded more favorable outcomes for men $(d=0.09,95 \% \mathrm{CI}=\mathbf{0 . 0 6 / 0 . 1 2})$. Homogeneity tests indicated that significant variability remained in each grouping of measures ( $p s<.05$ ).

Differences among measures can be evaluated through a comparison between classes $\left(Q_{B}\right)$, analogous to testing for main effects in analysis of variance models. The estimate $Q_{B}$ has an approximate chi-square distribution with $p-1$ degrees of freedom, in which $p$ represents the number of classes (Hedges \& Olkin, 1985). The sex-difference finding did vary significantly with type of measure $\left(Q_{\mathrm{B}}=80.18, p<.001\right)$. Post hoc comparisons between categories of measures (Hedges \& Olkin, 1985) revealed that happiness, positive affect, and life satisfaction were not significantly different from each other and that all measures differed from general evaluation $(p s<.01)$.

\section{Marital Role}

The effects of marriage were evaluated by using the percentage of the individuals in each study sample who were married as a predictor of the sex effect in a regression model. A least squares regression was calculated with each effect size weighted by the reciprocal of its variance (Hedges \& Olkin, 1985). The regression analysis yielded a test of the significance of the predictor as well as a test of model specification $\left(Q_{\mathrm{E}}\right)$, which evaluated whether significant unexplained variability remained in the effect sizes. The error sums-of-squares statistic, which provided this test of model adequacy, had an approximate chisquare distribution with $k-p-1$ degrees of freedom, in which $k$ is the number of effect sizes and $p$ is the number of predictors.
As can be seen in Table 3, the percentage of individuals in the study samples who were married proved to be a significant predictor of sex differences in well-being, such that studies in which a greater percentage of individuals were married obtained greater well-being of women than of men.

The effects of marriage on well-being were validated with the studies ( $n=14)$ using a representative sample of the population (see Table 3). The results continued to demonstrate that marriage is associated with more favorable outcomes for women than for men.

Interpreting effects associated with marital status. The regression analysis reveals that marital status is associated with sex differences in well-being, but it does not specify the exact pattern of this relationship. For example, a significant negative effect in the regression analysis could represent single men reporting greater well-being than single women yet represent no sex difference among married respondents. Alternatively, the effect may represent no sex difference among single respondents yet represent married women reporting greater well-being than married men.

To examine this issue, we conducted a median split on the percentage of the study sample that was married and used categorical analyses to compare the groups below and above the median (63\% married). Studies with few married participants ( $n=$ 28) yielded a sex difference favoring men $(d=0.08,95 \% \mathrm{CI}=$ $0.05 / 0.11)$. Studies with a greater percentage married $(n=28)$ yielded a sex difference favoring women $(d=-.07,95 \% \mathrm{CI}=$ $-0.10 /-0.04)$. These two study groupings were significantly different from each other $\left(Q_{\mathrm{B}}=71.39, p<.001\right)$, consistent with the regression results. Both groups proved significantly heterogeneous $(p s<.001)$. When those studies that sampled only married individuals were considered $(n=12)$, a somewhat larger sex difference was obtained $(d=-0.12,95 \% \mathrm{CI}=-0.19$ / -0.05 ), in further support of our predictions.

Another ambiguity that arises when interpreting this difference-score analysis is whether the result reflects men's or women's differential responses associated with the married versus unmarried state. The obtained sex difference could reflect women's responses if men's well-being remained relatively constant across married and unmarried states but women's wellbeing improved with marriage. Alternatively, the sex difference 
Table 3

Regression of Percentage of Study Sample Married on Sex Difference in Well-Being

\begin{tabular}{lccccc}
\hline \multicolumn{1}{c}{ Study sample } & $n$ & $b$ & $b^{*}$ & $R^{2}$ & $Q_{\mathrm{E}}$ \\
\hline Total sample of studies & 56 & $-.003^{* *}$ & -.44 & .20 & $231.05^{* *}$ \\
Studies using representative subject samples & 14 & $-.003^{*}$ & -.31 & .09 & $59.74^{* *}$ \\
\hline
\end{tabular}

Note. Models are weighted least squares regressions calculated with weights equal to the reciprocal of the variance for each effect size; $b=$ unstandardized regression coefficient, $b^{*}=$ standardized coefficient. Effect sizes are positive for differences in the male direction and are negative for differences in the female direction. $* p<.01$. ** $p<.001$.

could reflect men's responses if women's well-being remained relatively constant across married and unmarried states but men's well-being declined with marriage.

To examine which sex was responsible for the effect of marriage on well-being, we calculated $d$ statistics for each study providing the relevant data, to represent a comparison of the wellbeing of married men and that of unmarried men $(n=6)$ and a comparison of the well-being of married women and that of unmarried women $(n=6)$. Marriage proved to be associated with higher well-being than did the unmarried state for both $\operatorname{men}(d=0.49,95 \% \mathrm{CI}=0.42 / 0.55)$ and women $(d=0.54,95 \%$ $\mathrm{CI}=0.49 / 0.59$ ). Although in this small subset of studies the comparison between the results for men and for women was not significant $\left(Q_{\mathrm{B}}=1.59, n s\right)$, the direction of the data is consistent with the regression analysis in that it yields slightly larger gains in well-being associated with marriage for women than for men. Significant heterogeneity was obtained in the study groupings for men and for women $(p s<.01)$.

Type of well-being measure. The stability of the regression analysis predicting sex differences in well-being from percentage of study sample married was examined across type of wellbeing measure. First, a regression equation was calculated separately for each type of measure, with percentage married entered as a predictor of sex differences in well-being. Uniform results were obtained across all types of assessments: For life satisfaction $(n=14)$, happiness $(n=18)$, and general evaluation $(n=21)$, a higher percentage of married individuals was associated with greater well-being of women $(p s<.01)$. The exact form of this relation, however, varied across type of assessment. For life satisfaction $(n=9)$ and happiness $(n=6)$, no sex differences appeared in studies with few (63\% or less) married participants $(d=0.00,95 \% \mathrm{CI}=-0.06 / 0.06$, and $d=0.01,95 \% \mathrm{CI}=$ $-0.05 / 0.07$, respectively). For studies with a higher percentage of married participants, women reported greater happiness than men $(n=12, d=-0.08,95 \% \mathrm{CI}=-0.11 /-0.05)$ and nonsignificantly more life satisfaction $(n=5, d=-0.04,95 \%$ $\mathrm{CI}=-0.12 / 0.04)$. In contrast, for general evaluation measures, studies with few married participants $(n=12)$ yielded greater well-being of men $(d=0.14,95 \% \mathrm{CI}=0.11 / 0.17)$ and studies with a greater percentage of married participants $(n=9)$ yielded no sex difference $(d=0.00,95 \% \mathrm{CI}=-0.08 / 0.08)$. Too few positive affect assessments were available to conduct the analysis. $^{\text {? }}$

\section{Employment Role}

The effects of employment were evaluated by using the percentage of the individuals in each study sample who were employed as a predictor of sex effects in a regression model.
In the analysis on the complete set of studies, the percentage of total sample employed $(n=28)$ was a significant predictor of sex differences (unstandardized coefficient $=-.001, p<.05$ ), such that the greater percentage employed was associated with a larger sex difference favoring women. A significant amount of heterogeneity remained in the effect size estimates $(p<.001)$. The regression was also calculated on the subset of studies using a representative sample of respondents $(n=8)$. However, in this subset, employment proved not to be a significant predictor of well-being. Although we had originally planned to evaluate the effects of employment for each age level, because it is plausible that unique effects would be obtained with certain ages (e.g., retirement-aged persons), sufficient data were not available to conduct this analysis.

Thus the results for employment proved somewhat inconsistent, and adequate data were not available to assist in interpretation of these results. The possible differential effects of employment on men's and women's positive well-being awaits additional investigation (see Baruch, Biener, \& Barnett, 1987, Hirsh \& Rapkin, 1986, and Warr \& Parry, 1982, for relevant theoretical analyses).

\section{Distribution of Men's and Women's Ratings}

A basic assumption of the present analysis is that positive and negative aspects of well-being are independent and that wellbeing is best represented as two unipolar dimensions rather than as a single bipolar construct. Given our finding of greater happiness and life satisfaction in women (than in men), we expect a greater proportion of women than men to express extremely positive scores on these scales. However, we do not expect a sex difference in scores at the low end of the scales; although prior work has noted greater negative affect and psychological symptoms in women, respondents should be treating the assessment scales as representing a unipolar dimension of positive well-being. Men and women will not be expected to differ in ratings of absence of happiness or life satisfaction (i.e., low scores).

An effect size $(d)$ was calculated to represent the proportion of men to women at the extremes of the distribution of wellbeing scores. This was possible only for those studies reporting the frequency of men and women scoring at extremely high $(n=$

\footnotetext{
${ }^{7}$ The stability of the regression analysis that predicted well-being from percentage of sample married was examined with respect to two additional variables: respondents' mean age and the year the study was published. No consistent effects were obtained for either predictor.
} 
27) or extremely low ( $n=16)$ points on the well-being scale. In all cases, effect sizes were calculated from proportions via probit transformations (Glass et al., 1981). ${ }^{8}$ Effect sizes associated with more extreme women's well-being were given a negative sign, and those associated with more extreme men's wellbeing were given a positive sign.

The percentage of women reporting extremely high levels of well-being was greater than the percentage of men $(d=-0.05$, $95 \% \mathrm{CI}=-0.07 /-0.03$ ). A significant amount of variability existed within this grouping of studies $(p<.001)$. The percentage of women reporting extremely low levels of well-being did not differ from the percentage of men $(d=0.01,95 \% \mathrm{CI}=$ $-0.02 / 0.04)$. A significant amount of variability also existed within this grouping of studies $(p<.001)$.

Analyses were conducted to examine whether the sex difference in reports of extreme levels of well-being varied with type of assessment. As was anticipated for extreme positive well-being, a tendency was found for more women than men to report high levels of life satisfaction $(n=6 ; d=-0.05,95 \% \mathrm{CI}=$ $-0.10 / 0.00)$ and happiness $(n=15 ; d=-0.08,95 \% \mathrm{CI}=$ $-0.11 /-0.05)$. General evaluation measures $(n=6)$ yielded no sex difference $(d=0.02,95 \% \mathrm{CI}=-0.04 / 0.08)$. These estimates differed significantly from each other $\left(Q_{\mathrm{B}}=8.84, p<.05\right)$, and post hoc contrasts revealed that happiness differed from general evaluation $(p<.05)$, but no other comparisons were significant. All measures proved significantly heterogeneous $(p s<.01)$.

For extremely low ends of the well-being scales, no sex difference was obtained with life satisfaction measures $(n=6 ; d=$ $-0.03,95 \% \mathrm{CI}=-0.08 / 0.02)$ or happiness measures $(n=10$; $d=0.01,95 \% \mathrm{CI}=-0.02 / 0.04)$. General evaluation measures $(n=4)$ revealed more men than women reporting low well-being $(d=0.12,95 \% \mathrm{CI}=0.01 / 0.23)$. These effect sizes differed significantly from each other $\left(Q_{\mathrm{B}}=6.10, p<.05\right)$, and post hoc contrasts revealed that both happiness and life satisfaction differed from general evaluation ( $p s<.05$ ) but not from each other. A significant amount of variability existed in happiness and life satisfaction $(p s<.01)$ but not in general evaluation.

\section{Additional Predictors of Sex Effects}

Two moderators of the sex difference finding were considered: the mean age of respondents and the year the study was published. Age proved not to be a significant predictor of the sex effect. Year of publication was evaluated with a regression analysis predicting the sex difference in well-being from year $(n=$ 81). More recent studies tended to yield a stronger sex difference favoring men than did earlier ones (beta $=.01, p<.001$ ), and a significant amount of unexplained variability remained in the model $(p<.001)$.

To evaluate this effect in more detail, we conducted a median split on publication year, and earlier studies were compared to later ones $(M d n=1978)$. The earlier studies $(n=47)$ demonstrated a significant sex difference favoring women $(d=-0.05$, $95 \% \mathrm{CI}=-0.07 /-0.03)$, whereas later ones $(n=38)$ demonstrated an effect favoring men $(d=0.06,95 \% \mathrm{CI}=0.04 / 0.08$, $\left.Q_{\mathrm{B}}=65.81, p<.001\right)$. Both study groupings exhibited a significant amount of heterogeneity $(p s<.05)$.

The year effect was not apparent in analyses with studies using representative samples. A significant effect favoring women was obtained in earlier investigations $(n=12 ; d=-0.05,95 \%$ $\mathrm{CI}=-0.08 /-0.02$ ), and a nonsignificant trend in the same direction was obtained with studies published later $(n=6 ; d=$ $-0.03,95 \% \mathrm{CI}=-0.07 / 0.01$ ). These two study groupings did not differ from each other $\left(Q_{B}=0.86, n s\right)$. A significant amount of variability existed within each study grouping ( $p s<.05$ ).

Effects of year have been obtained in previous meta-analyses of sex differences in social behavior (Wood, 1987). It is always difficult to interpret such effects, because they can stem from a variety of factors, including actual social change as well as variations in measurement techniques and subject samples studied across time.

\section{Discussion}

We anticipated that women would report greater positive well-being than men. Our hypothesis derived from a consideration of men's and women's social roles. The female gender role prescribes greater emotional sensitivity and expressiveness; and furthermore, women's prior role enactment is more likely than men's to confer attitudes and skills consistent with emotional responsiveness (cf. Eagly, 1987; Eagly \& Wood, 1989).

We examined sex differences with respect to four measures of well-being: happiness, life satisfaction, positive affect, and a heterogeneous category labeled general evaluation. Consistent with our expectations, women reported greater happiness and life satisfaction than men, and positive affect yielded a nonsignificant trend in the same direction. In contrast, general evaluation measures yielded higher scores for men. These findings held for both the full set of studies and for the studies using samples representative of the U.S. population.

Our findings with the general evaluation measures are somewhat difficult to interpret, given the variety of scales included in this category. A number of these represent multiple-item measures that appear to assess both negative and positive aspects of experience. The greater well-being of men than of women in this grouping of studies is consistent with the findings of an earlier review that did not distinguish among types of measures (Haring et al., 1984). It is interesting to note that these results are also consistent with previous research on the negative aspects of well-being, revealing higher levels of depression, personal discomfort, and mental disorganization in women than in men (e.g., Gove \& Tudor, 1973; Nolen-Hoeksema, 1987). Perhaps the sex difference favoring men that we obtained in this study reflects scales that tapped, to some extent, the sex difference in negative affect and symptomatology.

Women's greater reports of happiness and life satisfaction documented in this review can be reconciled with these opposing findings if we assume that positive and negative well-being represent separate, unipolar dimensions (Diener et al., 1985). If greater emotionality is associated with the feminine than with the masculine gender role, then women will be expected to en-

\footnotetext{
${ }^{8}$ Our definition of extreme scores varied from study to study, because it depended on the number of scale points originally used and on how the data were aggregated for analysis. At the minimum, to be included in this analysis, studies needed to report a breakdown of low and moderate scores (for the extreme negative ratings) or moderate and high scores (for the extreme positive ratings) on the well-being scale.
} 
dese more extreme responses than will men on both positive and negative dimensions. Indeed, the distribution of sex difference responses in our research suggests that happiness and life satisfaction measures are unipolar: More women than men were represented in the extremely high end of the distribution of happiness scores, but no sex differences were obtained on the extremely low end of the scales. The measures we classified as general evaluation revealed a very different distribution of scores, suggestive of unipolar measures assessing negative wellbeing. However, the heterogeneity of studies in this grouping precludes interpreting the exact pattern of findings in any detail.

\section{Processes Underlying Sex Differences in Happiness and Life Satisfaction}

There are several points at which sex differences may arise in emotional experience. Men and women may differ in reporting internal affective states. In particular, it seems likely that women (rather than men) hold more accepting attitudes toward emotional expressiveness and believe that extreme emotional responses are socially sanctioned (Bradburn, 1969).

Sex differences also plausibly arise in awareness of internal emotional states. Women's past role-related experiences more likely confer skills associated with sensitivity to emotions and lead women to place a greater value on such insights. Social norms encouraging greater responsiveness in women (rather than in men) may further enhance women's sensitivity to their emotional states. Indeed, the greater emotional responsiveness of women than of men has been proposed as an explanation for sex differences in depression (Hammen \& Padesky, 1977; Nolen-Hoeksema, 1987). From this perspective, women adopt a style of coping with depressive feelings that emphasizes the negative emotions; they tend to ruminate about the causes and the implications of their mood. Men, in contrast, adopt a more active style of coping with depressive symptoms that involves engaging in distracting activities or ignoring the experience.

One way to conceptualize the relation between overt expression and personal experience of emotion is in terms of the correspondence between self-reports and physiological indicators. At least one investigation has found these to be related: Women's greater reports of fear of spiders seem to be accompanied by greater physiological reaction, as indicated by increased heart rate (Cornelius \& Averill, 1983).

From a theoretical standpoint, there is good reason to anticipate a close tie between private recognition and public reporting of emotional events. Overt behavior, such as saying one is happy, and internal experiences, or the feeling of happiness, may not be entirely separable in people's phenomenology. A respected tradition within social psychology holds that one often knows one's internal states from observing external responses (Bem, 1972). People are also motivated to maintain consistency among cognitive elements, so that private emotions may be modified to be consistent with public behavior (Wicklund \& Brehm, 1976). Indeed, empirical evidence supports the idea that, under some circumstances, people appear to adopt their own public expressions of self-enhancement or self-depreciation (Rhodewalt \& Agustsdottir, 1986), as well as expressions of emotions (Baumeister \& Cooper, 1981; Lanzetta, Cartwright-Smith, \& Kleck, 1976). This possibility has been noted in the context of sex differences in emotional experience: According to Briscoe (1982), norms encouraging women but not men to express feelings verbally may eventually result in women's greater awareness of their emotional states.

\section{Sex Differences in Experience of Marriage}

The sex differences in positive well-being that we obtained in this investigation can also be attributed to differential experience of marital roles. We anticipated that wives would be more likely than husbands to serve as emotional specialists in marriage. Such an outcome is consistent with gender-role expectations; furthermore women's (rather than men's) prior role enactment is more likely to confer appropriate attitudes and skills. Thus, when positive aspects of well-being were assessed, women were expected to report more favorable outcomes associated with marriage than were men.

To evaluate this idea, we used the percentage of participants in the original studies that were married as a predictor of sex differences in well-being. In effect, these analyses compared the size of the sex difference in well-being of married persons with the size of the sex difference obtained for those who were not: married, including the widowed, divorced, and never married.

In both the total set of studies and the subset using representative samples of respondents, marriage proved to be associated with greater benefits for women than for men. To interpret the sex difference, we compared the well-being of married persons with that of unmarried persons separately for men and women. Married individuals expressed much greater well-being than unmarried individuals, consistent with previous research (Glenn \& Weaver, 1979; Haring-Hidore et al., 1985). Although the small number of effect sizes included in this analysis did not yield a significant sex difference, the advantage associated with marriage was slightly stronger for women than for men.

Sex differences in the experience of marriage could underlie the sex difference obtained in life satisfaction and happiness because, for these measures, the studies using a small percentage of married respondents obtained no sex difference, and it was only those studies using a relatively high percentage of married persons that obtained greater happiness and (nonsignificantly) greater life satisfaction for women than for men. Thus the sex difference in overall happiness and life satisfaction could result from the tendency for most survey respondents to be married.

The pattern of sex differences obtained with general evaluation measures is more difficult to interpret, because it is not consistent with our measures of positive well-being or with prior research on negative affect and symptomatology (e.g., Gove, 1972). This rather confusing set of findings is presumably due to the heterogeneous nature of the general evaluation measures.

Although we have attributed the greater well-being of wives over husbands to sex differences in skills, attitudes, and normative expectations associated with the emotional aspects of marriage, alternate interpretations are certainly possible. For example, Gove (1972; Gove \& Tudor, 1973) attributed wives' greater negative affect and psychological symptomatology in comparison with those of husbands' to structural aspects of marital roles that result in poorer outcomes for wives (e.g., loneliness, lack of social recognition, boredom). To explain the findings for 
positive well-being, we would need to extend this argument to consider the uniquely positive consequences of marital roles for women. For example, we can speculate that marriage allows women rather than men greater flexibility to select particular life-styles. Women, on the average, may have more choice in deciding whether to work or stay home, and this could result in greater positive well-being on the part of wives.

Sex differences in objective life circumstances such as these may affect subjective well-being in a variety of ways. From one perspective, evaluations of well-being result from a comparison of one's current life experiences with an internal standard. This standard may be derived from comparisons with others (Brickman \& Janoff-Bulman, 1977; Emmons \& Diener, 1985), one's previous experiences (Brickman, Coates, \& Janoff-Bulman, 1978; Parducci, 1968), and one's aspirations and goals (Emmons, 1986). Sex differences in well-being will thus derive from one sex perceiving a greater divergence between current outcomes and their judgment standard.

Evidence on this point is available from research on well-being of employed persons. In evaluating employment-related outcomes, workers appear to select reference others who are of the same sex as themselves and who perform similar jobs (Crosby, 1982; Major, 1987). Thus, for example, women may recognize that their salary is only $64 \%$ of men's, but they select other women as a reference group and consequently express a satisfaction with their level of pay that is equal to men's satisfaction (cf. Major, 1987). From this perspective, the sex differences in happiness and life satisfaction we obtained would emerge only when sex differences in evaluations of life circumstances were not accompanied by complementary sex differences in reference standards.

\section{Conclusion}

The greater reported happiness and life satisfaction of women in comparison with that of men documented in our review may be termed a small effect. Even among married respondents, the sex difference was not of a large magnitude. In our attempts to explain the difference between men's and women's judgments, respondents' marital role did prove to account for a reasonable amount of the variance in this sex difference.

It would be inappropriate to label these effects trivial simply as a function of their size. Their importance becomes apparent when placed in the perspective of prior research on negative aspects of subjective well-being. Our results are impressive in that the obtained pattern so closely mirrors that found with negative affect and symptomatology (Gove, 1972; Gove \& Tudor, 1973) and with depression (Nolen-Hoeksema, 1987; Radloff, 1975, 1980). That is, women appear to express more extreme levels of positive and negative well-being than do men, and furthermore, the results obtain primarily among married respondents.

Our explanation for these complementary findings emphasized men's and women's social roles. This perspective is particularly attractive in its ability to account for sex differences in positive and negative aspects of experience within a single framework, along with the obtained variation in the sex differences according to respondents' marital roles. However, it is important to recognize that the sex differences we documented in happiness and life satisfaction appear smaller than the sex differences typically found in the literature on depression and psychological symptomatology, although data are not available for exact comparison. Thus women's tendency to report greater happiness and life satisfaction in comparison with that of men appears to coexist with a larger tendency to report greater negative well-being. Indeed, it may be that mechanisms in addition to role factors contribute to sex differences in negative affect and symptomatology, including socialization pressures and biological processes.

Finally, it is worth reiterating our conclusions in the context of the questions that generated much of the research we reviewed: "Do men or women in our society possess greater wellbeing?" and "Is marriage better for men or women?" Although our investigation focused on very specific indicators of subjective experience, the obtained effects suggest general differences in characteristic emotional styles of men and women in our society. We believe that women are more likely than men to be sensitive to and expressive of emotional experiences, and this is particularly the case with emotional aspects of intimate relationships. Thus women may be more responsive than men to emotional highs and lows, particularly when involved in close relationships. Because men and women appear to differ in both positive and negative well-being, no clear advantage can be identified in the adaptiveness and desirability of their different styles of emotional life.

\section{References}

Allen, J. G., \& Haccoun, D. M. (1976). Sex differences in emotionality: A multi-dimensional approach. Human Relations, 29, 711-722.

Allen, J. G., \& Hamsher, J. H. (1974). The development and validation of a test of emotional styles. Journal of Consulting and Clinical Psychology, 42, 663-668.

Amenson, C. S., \& Lewinsohn, P. M. (1981). An investigation into the observed sex difference in prevalence of unipolar depression. Journal of Abnormal Psychology, 90, 1-13.

Andrews, F. M., \& Withey, S. B. (1976). Social indicators of well-being. New York: Plenum Press.

Aneshensel, C. S., Frerichs, R. R., \& Clark, V. A. (1981). Family role and sex differences in depression. Journal of Health and Social Behavior, 22, 379-393.

Averill, J. R. (1983). Studies on anger and aggression: Implications for theories of emotion. American Psychologist, 38, 1145-1 160.

Balswick, J., \& Avertt, C. P. (1977). Differences in expressiveness: Gender, interpersonal orientation, and perceived parental expressiveness as contributing factors. Journal of Marriage and the Family, 39, 121127.

Baruch, G. K., Biener, L., \& Barnett, R. C. (1987). Women and gender in research on work and family stress. American Psychologist, 42, 130-136.

Baumeister, R. F., \& Cooper, J. (1981). Can the public expectation of emotion cause that emotion? Journal of Personality, 49, 49-59.

Belle, D. (1980). Who uses mental health facilities? In M. Guttentag, S. Salasin, \& D. Belle (Eds.), The mental health of women (pp. 1-20). New York: Academic Press.

Belle, D., \& Goldman, N. (1980). Patterns of diagnoses received by men and women. In M. Guttentag, S. Salasin, \& D. Belle (Eds.), The mental health of women (pp. 21-30). New York: Academic Press.

Bem, D. J. (1972). Self-perception theory. In L. Berkowitz (Ed.), Advances in experimental social psychology (Vol. 6, pp. 1-62). New York: Academic Press. 
Bernard, J. (1972). The future of marriage. New York: Bantam Books. Bradburn, N. M. (1969). The structure of psychological well-being. Chicago: Aldine.

Brickman, P., Coates, D., \& Janoff-Bulman, R. (1978). Lottery winners and accident victims: Is happiness relative? Journal of Personality and Social Psychology, 36, 917-927.

Brickman, P., \& Janoff-Bulman, R. (1977). Pleasure and pain in social comparison. In J. M. Suls \& R. L. Miller (Eds.), Social comparison processes: Theoretical and empirical perspectives (pp. 149-186). Washington, DC: Hemisphere.

Briscoe, M. (1982). Sex differences in psychological well-being. Psychological Medicine, Monograph Supplement, 1, 1-46.

Broverman, I. K., Vogel, S. R., Broverman, D. M., Clarkson, F. E., \& Rosenkrantz, P. S. (1972). Sex-role stereotypes: A current appraisal. Journal of Social Issues, 28, 59-78.

Bryant, F. B., \& Veroff, J. (1982). The structure of psychological wellbeing: A sociohistorical analysis. Journal of Personality and Social Psychology, 43, 653-673.

Bryson, S. E., \& Pilon, D. J. (1984). Sex differences in depression and the method of administering the Beck Depression Inventory. Journal of Clinical Psychology, 40, 529-534.

Campbell, A. (1981). The sense of well-being in America: Recent patterns and trends. New York: McGraw-Hill.

Carroll, B. J., Feinberg, M., Smouse, P. E., Rawson, S. G., \& Greden, J. F. (1981). The Carroll rating scale for depression: Development, reliability, and validation. British Journal of Psychiatry, 138, 194200.

Clancy, K., \& Gove, W. (1974). Sex differences in mental illness: An analysis of response bias in self-reports. American Journal of Sociology, 80, 205-216.

Cochrane, R. (1983). The social creation of mental illness. London: Longman.

Cohen, S.,\& Wills, T. A. (1985). Stress, social support, and the buffering hypothesis. Psychological Bulletin, 98, 310-357.

Cornelius, R. R., \& Averill, J. R. (1983). Sex differences in fear of spiders. Journal of Personality and Social Psychology, 45, 377-383.

Coser, L. A. (1974). Greedy institutions. New York: Free Press.

Crosby, F. J. (1982). Relative deprivation and working women. New York: Oxford University Press.

Darley, S. A. (1976). Big-time careers for the little woman: A dual-role dilemma. Journal of Social Issues, 32, 85-98.

Diener, E. (1984). Subjective well-being. Psychological Bulletin, 95, 542-575.

Diener, E., \& Griffin, S. (1984). Happiness and life satisfaction. Psychological Documents, 14, 11.

Diener, E., Larson, R. J., Levine, S., \& Emmons, R. A. (1985). Intensity and frequency: Dimensions underlying positive and negative affect. Journal of Personality and Social Psychology, 48, 1253-1265.

Dion' K. K., \& Dion, K. L. (1985). Personality, gender, and the phenomenology of romantic love. In P. Shaver (Ed.), Self, situation, and social behavior: Review of personality and social psychology (Vol. 6, pp. 209-239). Beverly Hills, CA: Sage.

Dohrenwend, B. P., \& Dohrenwend, B. S., (1976). Sex differences and psychiatric disorders. American Journal of Sociology, 81, 1447-1454.

Dohrenwend, B. P., \& Dohrenwend, B. S. (1977). Reply to Gove and Tudor's comment on "Sex differences and psychiatric disorders." American Journal of Sociology, 82, 1336-1345.

Eagly, A. H. (1987). Sex differences in social behavior: A social-role interpretation. Hillsdale, $\mathrm{NJ}$ : Erlbaum.

Eagly, A. H., \& Wood, W. (1989). Explaining sex differences in social behavior: A meta-analytic perspective. Manuscript submitted for publication.

Emmons, R. A. (1986). Personal strivings: An approach to personality and subjective well-being. Journal of Personality and Social Psychology, 51, 1058-1068.

Emmons, R. A., \& Diener, E. (1985). Factors predicting satisfaction judgments: A comparative examination. Social Indicators Research, 16, 157-167.

Epstein, S. (1983). A research paradigm for the study of personality and emotions. In H. Howe \& R. Dienstbier (Eds.), Nebraska symposium on motivation: 1982 (pp. 91-154). Lincoln: Nebraska University Press.

Fox, J. W. (1980). Gove's specific sex-role theory of mental illness: A research note. Journal of Health and Social Behavior, 21, 260-267.

Freedman, J. (1978). Happy people. New York: Harcourt Brace Jovanovich.

Friedan, B. (1963). The feminine mystique. New York: Norton.

Glass, G. V., McGaw, B., \& Smith, M. L. (1981). Meta-analysis in social research. Beverly Hills, CA: Sage.

Glenn, N. D. (1975). The contribution of marriage to the psychological well-being of males and females. Journal of Marriage and the Family, 37, 594-600.

Glenn, N. D., \& Weaver, C. N. (1979). A note on family situation and global happiness. Social Forces, 57, 960-967.

Glenn, N. D., \& Weaver, C. N. (1981). The contribution of marital happiness to global happiness. Journal of Marriage and the Family,j43, 161-168.

Glenn, N. D., \& Weaver, C. N. (1988). The changing relationship of marital status to reported happiness. Journal of Marriage and the Family, 50, 317-324.

Goldman, N., \& Ravid, R. (1980). Community surveys and sex differences in mental illness. In M. Guttentag, S. Salasin, \& D. Belle (Eds.), The mental health of women (pp. 31-55). New York: Academic Press.

Goode, W. J. (1960). A theory of role strain. American Sociological Review, 25, 483-496.

Gove, W. R. (1972). The relationship between sex roles, marital status, and mental illness. Social Forces, 51, 34-44.

Gove, W. R. (1978). Sex differences in mental illness among adult men and women: An evaluation of four questions regarding the evidence on the higher rates of women. Social Science and Medicine, 12B, 187198.

Gove, W. R., \& Geerken, M. R. (1977). Response bias in surveys of mental health: An empirical investigation. American Journal of Sociology, 82, 1289-1317.

Gove, W. R., Hughes, M., \& Style, C. B. (1983). Does marriage have positive effects on the psychological well-being of the individual? Journal of Health and Social Behavior, 24, 122-131.

Gove, W. J., McCorkel, J., Fain, T., \& Hughes, M. D. (1976). Response bias in community surveys of mental health: Systematic bias or random noise? Social Science and Medicine, 10, 497-502.

Gove, W. R., \& Tudor, J. F. (1973). Adult sex roles and mental illness. American Journal of Sociology, 78, 812-835.

Hamilton' D. L. (1968). Personality attributes associated with extreme response styles. Psychological Bulletin, 3, 192-203.

Hammen; C. L., \& Padesky, C. A. (1977). Sex differences in the expression of depressive responses on the Beck Depression Inventory. Journal of Abnormal Psychology, 6, 609-614.

Haring, M. J., Stock, W. A., \& Okun, M. A. (1984). A research synthesis of gender and social class as correlates of subjective well-being. $\mathrm{Hu}$ man Relations, 37, 645-657.

Haring-Hidore, M., Stock, W. A., Okun, M. A., \& Witter, R. A. (1985). Marital status and subjective well-being: A research synthesis. Journal of Marriage and the Family, 47, 947-953.

Hedges, L. V., \& Olkin, I. (1985). Statistical methods for meta-analysis. Orlando, FL: Academic Press.

Hirsh, B. J., \& Rapkin, B. D. (1986). Multiple roles, social networks, 
and women's well-being. Journal of Personality and Social Psychology, 51, 1237-1247.

Huston, T. L., \& Ashmore, R. D. (1986). Women and men in personal relationships. In R. D. Ashmore \& F. K. DelBoca (Eds.), The social psychology of female-male relations (pp. 167-210). Orlando, FL: Academic Press.

Kessler, R. C., Brown, R. L., \& Broman, C. L. (1981). Sex differences in psychiatric help-seeking: Evidence from four large-scale surveys. Journal of Health and Social Behavior, 22, 49-64.

King', D. A., \& Buchwald, A. M. (1982). Sex differences in subclinical depression: Administration of the Beck Depression Inventory in public and private disclosure situations. Journal of Personality and Social Psychology, 42, 963-969.

Kohn, A. R., \& Fiedler, F. E. (1961). Age and sex differences in the perception of persons. Sociometry, 24, 157-163.

Lanzetta, J., Cartwright-Smith, J., \& Kleck, R. E. (1976). Effects of nonverbal dissimulation on emotional experience and autonomic arousal. Journal of Personality and Social Psychology, 33, 354-370.

Levenson, R. W., \& Gottman, J. M. (1985). Physiological and affective predictors of change in relationship satisfaction. Journal of Personality and Social Psychology, 49, 85-94.

Link, B., \& Dohrenwend, B. F. (1980). Formulation of hypotheses about the ratio of untreated to treated cases in the true prevalence studies of functional psychiatric disorders in adults in the United States. In B. P. Dohrenwend, B. S. Dohrenwend, M. S. Gould, B. Link, R. Neugebauer, \& R. Wunsch-Hitzig (Eds.), Mental illness in the United States: Epidemiological estimates. New York: Praeger.

Lohmann, N. (1977). Correlations of life satisfaction, morale and adjustment measures. Journal of Gerontology, 32, 73-75.

Major, B. (1987). Gender, justice, and the psychology of entitlement. In P. Shaver \& C. Hendrick (Eds.), Sex and gender: Review of personality and social psychology (Vol. 7, pp. 124-148). Beverly Hills, CA: Sage.

Marks, S. R. (1977). Multiple roles and role strain: Some notes on human energy, time, and commitment. American Sociological Review, 42, 921-936.

Neugebauer, R., Dohrenwend, B. P., \& Dohrenwend, B. S. (1980). Formulation of hypotheses about the true prevalence of psychiatric disorders among adults in the United States. In B. P. Dohrenwend, B. S. Dohrenwend, M. S. Gould, B. Link, R. Neugebauer, \& R. WunschHitzig (Eds.), Mental illness in the United States: Epidemiological estimates. New York: Praeger.

Nolen-Hoeksema, S. (1987). Sex differences in unipolar depression: Evidence and theory. Psychological Bulletin, 101, 259-282.

Notarius, C. J., \& Johnson, J. F. (1982). Emotional expression in husbands and wives. Journal of Marriage and the Family, 44, 483-489.

Parducci, A. (1968). The relativism of absolute judgments. Scientific American, 219 (December), 84-90.

Pearlin, L. I., \& Johnson, J. S. (1977). Marital status, life-strains, and depression. American Sociological Review, 42, 704-715.

Peplau, L. A. (1983). Roles and gender. In H. H. Kelley, E. Berscheid, A. Christensen, J. H. Harvey, T. L. Huston, G. Levinger, E. McClintock, L. A. Peplau, \& D. R. Peterson (Eds.), Close relationships. New York: W. H. Freeman.

Phillips, D. L., \& Segal, B. E. (1969). Sexual status and psychiatric symptoms. American Sociological Review, 34, 58-72.
Radloff, L. (1975). Sex differences in depression: The effects of occupation and marital status. Sex Roles, 1, 249-265.

Radloff, L. S. (1980). Risk factors from depression: What do we learn from them? In M. Guttentag, S. Salasin, \& D. Belle (Eds.), The mental health of women (pp. 93-109). New York: Academic Press.

Reedy, M. N., Birren, J. E., \& Schaie, K. W. (1981). Age and sex differences in satisfying love relationships across the adult life span. $\mathrm{Hu}$ man Development, 24, 52-66.

Reis, H. T., Senchak, M., \& Solomon, B. (1985). Sex differences in the intimacy of social interaction: Further examination of potential explanations. Journal of Personality and Social Psychology, 48, 12041217.

Rhodewalt, F., \& Agustsdottir, S. (1986). Effect of self-presentation on the phenomenal self. Journal of Personality and Social Psychology. 50, 47-55.

Rosenthal, R. (1984). Meta-analytic procedures for social research. Beverly Hills, CA: Sage.

Ruble, T. (1983). Sex stereotypes: Issues of change in the 1970s. Sex Roles, 9, 397-402.

Seiden, A. M. (1976). Overview: Research on the psychology of women: II. Women in families, work, and psychotherapy. The American Journal of Psychiatry, 133, 1111-1123.

Sieber, S. D. (1974). Toward a theory of role accumulation. American Sociological Review, 39, 567-578.

Smith, E. R., \& Kleugel, J. R. (1982). Cognitive and social bases of emotional experience: Outcome, attribution, and affect. Journal of Personality and Social Psychology, 43, 1129-1141.

Stock, W. A., Okun, M. A., Haring, M. J., \& Witter, R. A. (1983). Age differences in subjective well-being. In R. J. Light (Ed.), Evaluation studies: Review annual (Vol. 8, pp. 279-302). Beverly Hills, CA: Sage.

Thoits, P. A. (1983). Multiple identities and psychological well-being: A reformulation and test of the social isolation hypothesis. American Sociological Review, 48, 174-187.

Thoits, P. A. (1986). Multiple identities: Examining gender and marital status differences in distress. American Sociological Review, 51,259272.

Tudor, W., Tudor, J. F., \& Gove, W. R., (1977). The effect of sex role differences on the social control of mental illness. Journal of Health and Social Behavior, 18, 98-112.

Warr, P. B. (1971). Pollyanna's personal judgments. European Journal of Social Psychology, 1, 328-337.

Warr, P., Barter, J., \& Brownbridge, G. (1983). On the independence of positive and negative affect. Journal of Personality and Social Psychology, 44, 644-651.

Warr, P., \& Parry, G. (1982). Paid employment and women's psychological well-being. Psychological Bulletin, 91, 498-516.

Weissman, M. M., \& Klerman, G. L. (1977). Sex differences and the epidemiology of depression. Archives of General Psychiatry, 34, 98111.

Wicklund, R. A., \& Brehm, J. W. (1976). Perspectives on cognitive dissonance. Hillsdale, $\mathrm{NJ}$ : Erlbaum.

Williams, J. E., \& Best, D. L. (1982). Measuring sex stereotypes: A thirty-nation study. Beverly Hills, CA: Sage.

Wood, W. (1987). Meta-analytic review of sex differences in group performance. Psychological Bulletin, 102, 53-71. 


\section{Appendix}

\section{Studies Used in the Meta-Analysis}

Alston, J. P., \& Dudley, C. J. (1973). Age, occupation, and life satisfaction: Gerontologist, 13, 58-61.

Andrews, F. M., \& Withey, S. B. (1976). Social indicators of well-being. New York: Plenum Press.

Baur, P. A., \& Okun, M. A. (1983). Stability of life satisfaction in late life. Gerontologist, 23, 261-265.

Borges, M. A., Levine, J. R., \& Dutton, L. J. (1984). Men's and women's ratings of life satisfaction by age of respondent and age interval judged. Sex Roles, 11, 345-350.

Botwinick, J., \& Storandt, M. (1974). Memory, related functions, and age. Springfield, IL: Charles $C$ Thomas.

Bradburn, N. M. (1969). The structure of psychological well-being. Chicago: Aldine.

Brand, F. N., \& Smith, R. T. (1974). Life adjustment and relocation of the elderly. Journal of Gerontology, 29, 336-340.

Brayfield, A. H., Wells, R. V., \& Strate, M. W. (1957). Interrelationships among measures of job satisfaction and general satisfaction. Journal of Applied Psychology, 41, 201-205.

Briscoe, M. (1978). Sex differences in perception of illness and expressed life satisfaction. Psychological Medicine, 8, 339-345.

Briscoe, M. (1982). Sex differences in psychological well-being, Psychological Medicine, Monograph Supplement, 1, 1-46.

Bronzaft, A. L., \& Hayes, R. F. (1983). Family characteristics and life satisfaction of high academic achievers. Mankind Quarterly, 24, 3759.

Bulatao, R. A. (1974). Measures of happiness among Manila residents. Philippine Sociological Review, 21, 229-238.

Burke, R. J., \& Weir, T. (1976). Relationship of wives' employment status to husband, wife and pair satisfaction and performance. Journal of Marriage and the Family, 38, 279-287.

Burke, R. J., \& Weir, T. (1978). Sex differences in adolescent life stress, social support, and well-being. Journal of Psychology, 98, 277-288.

Cameron, P. (1972). Stereotypes about generational fun and happiness vs. self-appraised fun and happiness. Gerontologist, 12, 120-123, 190.

Campbell, A., Converse, P. E., \& Rodgers, W. L. (1976). The quality of American life. New York: Russell Sage Foundation.

Cantril, H. (1965). The pattern of human concerns. New Brunswick, NJ: Rutgers University Press.

Cavan, R. S., Burgess, E. W., Havighurst, R. J., \& Goldhamer, H. (1949). Personal adjustment in old age. Chicago: Science Research Associates.

Chilman, C. S., \& Meyer, D. L. (1966). Single and married undergraduates' measured personality needs and self-rated happiness. Journal of Marriage and the Family, 28, 67-76.

Chiriboga, D. A., Roberts, J., \& Stein, J. A. (1978). Psychological wellbeing during marital separation. Journal of Divorce, 2, 21-36.

Collette, J. (1984). Sex differences in life satisfaction: Australian data. Journal of Gerontology, 39, 243-245.

Council on Aging (1972). Social indicators for the aged. Atlanta, GA: Department of Human Resources.

Crandall, J. E., \& Kytonen, J. A. (1980). Sex, age, and stress as moderators for the relation between social interest and well-being. Journal of Individual Psychology, 36, 169-182.

Critelli, J. W. (1977). Romantic attraction and happiness. Psychological Reports, 41, 721-722.

Czaja, S. J. (1975). Age differences in life satisfaction as a function of discrepancy between real and ideal self concepts. Experimental Aging Research, 1, 81-89.

Dickie, J. R., Ludwig, T. E., \& Blauw, D. (1979). Life satisfaction among institutionalized and non-institutionalized older adults. Psychological Reports, 44, 807-810.

Dillard, J. M., Campbell, N. J., \& Chisolm, G. B. (1984). Correlates of life satisfaction of aged persons. Psychological Reports, 54, 977-978.

Dressler, D. M. (1973). Life adjustment of retired couples. International Journal of Aging and Human Development, 4, 335-349.

Edwards, J. N., \& Klemmack, D. L. (1973). Correlates of life satisfaction: A re-examination. Journal of Gerontology, 28, 497-502.

Flint, G. A., Gayton, W. F., \& Ozmon, K. L. (1983). Relationship between life satisfaction and acceptance of death by elderly persons. Psychological Reports, 53, 290.

Gilhooly, M. L. M. (1984). The impact of care-giving on care-givers: Factors associated with the psychological well-being of people supporting a dementing relative in the community. British Journal of Medical Psychology, 57, 35-44.

Gilleard, C. J., Willmott, M., \& Vaddadi, K. S. (1981). Self-report measures of mood and morale in elderly depressives. British Journal of Psychiatry, 138, 230-235.

Glenn, N. D. (1975). The contribution of marriage to the psychological well-being of males and females. Journal of Marriage and the Family 37, 594-601.

Gove, W. R. (1978). Sex differences in mental illness among adult men and women: An evaluation of four questions raised regarding the evidence on the higher rates of women. Social Science and Medicine, 12, 187-198.

Grant, K. R., \& Chappell, N. L. (1983). Life satisfaction and functional disability among day hospital participants. Social Science and Medicine, 17, 71-78.

Grichting, W. L. (1983). Domain, scope and degree of happiness. British Journal of Social Psychology, 22, 247-260.

Gurin, G., Veroff, J., \& Feld, S. (1960). Americans view their mental health. New York: Basic Books.

Haavio-Mannila, E. (1971). Satisfaction with family, work, leisure and life among men and women. Human Relations, 24, 585-601.

Harding, S. D. (1982). Psychological well-being in Great Britain: An evaluation of the Bradburn Affect-Balance Scale. Personality and Individual Differences, 3, 167-175.

Harel, Z., \& Noelker, L. (1982). Social integration, health, and choice. Research on Aging, 4:97-111.

Hayes, M. P., \& Stinnett, N. (1971). Life satisfaction of middle-aged husbands and wives. Journal of Home Economics, 63, 669-674.

Hearn, J. C. (1980). Major choice and the well-being of college men and women: An examination from developmental, organizational, and structural perspectives. Sociology of Education, 53, 164-178.

Henley, B., \& Davis, M. S. (1967). Satisfaction and dissatisfaction: A study of the chronically-ill aged patient. Journal of Health and Social Behavior, 8, 65-75.

Hingson, R., Scotch, N., Barrett, J., Goldman, E., \& Mangione, T. (1981). Life satisfaction and drinking practices in the Boston metropolitan area. Journal of Studies on Alcohol, 42, 24-36.

Holahan, C. K., \& Gilbert, L. A. (1979). Conflict between major life roles: Women and men in dual career couples. Human Relations, 32, 451-467.

Hoyt, D. R., Kaiser, M. A., Peters, G. R., \& Babchuk, N. (1980). Life satisfaction and activity theory: A multi-dimensional approach. Journal of Gerontology, 35, 935-941.

Hutchinson, I. W. III. (1975). The significance of marital status for morale and life satisfaction among lower-income elderly. Journal of Marriage and the Family, 37, 287-293.

Inglehart, R. (1978). Value priorities, life satisfaction, and political dis- 
satisfaction among Western publics. Comparative Studies in Sociology, 1, 173-202.

Kammann, R. (1983). Objective circumstances, life satisfaction, and sense of well-being: Consistencies across time and place. New Zealand Journal of Psychology, 12, 14-22.

Knapp, M. R. J. (1976). Predicting the dimensions of life satisfaction. Journal of Gerontology, 31, 595-604.

Knupfer, G., Clark, W., \& Room, R. (1966). The mental health of the unmarried. American Journal of Psychiatry, 122, 841-851.

Kurtz, J. J., \& Wolk, S. (1975). Continued growth and life satisfaction. Gerontologist, 15, 129-131.

Kushman, J., \& Lane, S. (1980). A multivariate analysis of factors affecting perceived life satisfaction and psychological well-being among the elderly. Social Science Quarterly, 61, 264-277.

Kutner, B., Fanshel, D., Togo, A. M., \& Langner, T. S. (1956). Five hundred over sixty. New York: Russell Sage Foundation.

Lawrence, O. E., \& Guy, R. F. (1980). Assessment of methods for measuring life satisfaction. Free Inquiry in Creative Sociology, 8, 181185.

Lawton, M. P. (1972). The dimensions of morale. In D. P. Kent, R. Kastenbaum, \& S. Sherwood (Eds.), Research planning and action for the elderly. New York: Behavioral Publications.

Lawton, M. P., Moss, M., \& Moles, E. (1984). The suprapersonal neighborhood context of older people: Age heterogeneity and well-being. Environment and Behavior, 16, 89-109.

Lee, G. R. (1978). Marriage and morale in later life. Journal of Marriage and the Family, 40, 131-139.

Lee, G. R., \& Ellithorpe, E. (1982). Intergenerational exchange and subjective well-being among the elderly. Journal of Marriage and the Family, 44, 217-224.

Liang, J.' (1982), Sex differences in life satisfaction among the elderly. Journal of Gerontology, 37, 100-108.

Lieberman, L. R. (1970). Life satisfaction in the young and the old. Psychological Reports, 27, 75-79.

Lipman, A. (1961). Role conceptions and morale of couples in retirement. Journal of Gerontology, 16, 267-271.

Lowry, J. H. (1984). Life satisfaction time components among the elderly. Research on Aging, 6, 417-431.

Lubinski, D., Tellegen, A., \& Butcher, J. (1981). The relationship between androgyny and subjective indicators of emotional well-being. Journal of Personality and Social Psychology, 40, 722-730.

Maddox, G., \& Eisdorfer, C. (1962). Some correlates of activity and morale among the elderly. Social Forces, 40, 254-260.

Messer, M. (1968). Race differences in selected attitudinal dimensions of the elderly. Gerontologist, 8, 245-249.

Michalos, A. C. (1980). Satisfaction and happiness. Social Indicators Research, 8, 385-422.

Michalos, A. C. (1982). The satisfaction and happiness of some senior citizens in rural Ontario. Social Indicators Research, 11, 1-30.

Mugford, S., \& Lally, J. (1981). Sex, reported happiness, and the wellbeing of married individuals: A test of Bernard's hypothesis in an Australian sample. Journal of Marriage and the Family, 43, 969-975.

Mutran, E., \& Reitzes, D. C. (1984). Intergenerational support activities and well-being among the elderly: A convergence of exchange and symbolic interaction perspectives. American Sociological Review, 49, 117-130.

Nehrke, M. F., Bellucci, G., \& Gabriel, S. J. (1977-1978). Death anxiety, locus of control and life satisfaction in the elderly: Toward a definition of ego-integrity. Omega, 8, 359-367.

Noelker, L. S., \& Harel, Z. (1982). Residential choice and the well-being of aged and disabled public housing residents. Journal of Gerontologi: cal Social Work, 4, 17-29.

Nussbaum, J. F. (1983). Relational closeness of elderly interaction: Implications for life satisfaction. Western Journal of Speech Communication, 47, 229-243.

Ochse, R. (1984). Measuring global life satisfaction in South Africa. South African Journal of Psychology, 14, 60-63.

Palmore, E., \& Luikart, C. (1972). Health and social factors related to life satisfaction. Journal of Health and Social Behavior, 13, 68-79.

Phillips, D. L. (1967). Social participation and happiness. American Journal of Sociology, 72, 479-488.

Reed, W. L., \& Washington, B. B. (1984). Social well-being of institutionalized elderly persons. International Journal of Aging and Human Development, 19, 311-318.

Rosenberg, E., \& Chelte, A. F. (1980). Avowed happiness of members of sport and non-sport voluntary associations. International Journal of Sport Psychology, 11, 263-274.

Runyan, W. M. (1980). The life satisfaction chart: Perceptions of the course of subjective experience. International Journal of Aging and Human Development, 11, 45-64.

Schmitt, N., White, J. K., Coyle, B. W., \& Rauschenberger, J. (1979). Retirement and life satisfaction. Academy of Management Journal, 22, 282-291.

Sekaran, U. (1986). Significant differences in quality-of-life factors and their correlates: A function of differences in career orientations or gender? Sex Roles, 14, 261-279.

Shichman, S., \& Cooper, E. (1984). Life satisfaction and sex-role concept. Sex Roles, 11, 227-240.

Shin, D. C., \& Johnson, D. M. (1978). Avowed happiness as an overall assessment of the quality of life. Social Indicators Research, 5, 475492.

Smith, E. R., \& Kluegel, J. R. (1982). Cognitive and social bases of emotional experience: Outcome, attribution, and affect. Journal of Personality and Social Psychology; 43, 1129-1141.

Snider, E. L. (1980). Explaining life satisfaction: It's the elderly's attitudes that count. Social Science Quarterly, 61, 253-263.

Storandt, M., Wittels, I., Botwinick, J. (1975). Predictors of a dimension of well-being in the relocated healthy aged. Journal of Gerontology, 80, 97-102.

Tolor, A. (1978). Personality correlates of the joy of life. Journal of Clinical Psychology, 34, 671-676.

Toseland, R., \& Sykes, J. (1977). Senior citizens center participation and other correlates of life satisfaction, Gerontologist, 17, 235-241.

Veroff, J., Douvan, E., \& Kulka, R. A. (1981). The inner American. New York: Basic Books.

Wenz, F. V. (1977). Neighborhood type, social disequilibrium, and happiness. Psychiatric Quarterly, 49, 187-196.

White, L. K. (1979). Sex differentials in the effect of remarriage on global happiness. Journal of Marriage and the Family, 41, 869-876.

Wilkening, E. A., \& McGranahan, D. (1978). Correlates of subjective well-being in northern Wisconsin. Social Indicators Research, 5 211-234.

Woods, N., \& Witte, K. L. (1981). Life satisfaction, fear of death, and ego identity in elderly adults. Bulletin of the Psychonomic Society, 18 , 165-168.
Received April 18, 1988

Revision received November 9, 1988 Accepted November 23, 1988 